\title{
A lucrative chemical processing of bamboo leaf biomass to synthesize biocompatible amorphous silica nanoparticles of biomedical importance
}

\author{
Suriyaprabha Rangaraj ${ }^{1} \cdot$ Rajendran Venkatachalam $^{1}$ (D)
}

Received: 30 January 2017/ Accepted: 16 March 2017/Published online: 28 March 2017

(c) The Author(s) 2017. This article is an open access publication

\begin{abstract}
Synthesis of silica nanoparticles from natural resources/waste via cost effective route is presently one of the anticipating strategies for extensive applications. This study reports the low-cost indigenous production of silica nanoparticles from the leftover of bamboo (leaf biomass) through thermal combustion and alkaline extraction, and examination of physico-chemical properties and yield percentage using comprehensive characterization tools. The outcome of primed silica powder exhibits amorphous particles (average size: $25 \mathrm{~nm}$ ) with high surface area $\left(428 \mathrm{~m}^{2} \mathrm{~g}^{-1}\right)$ and spherical morphology. Despite the yield percentage of silica nanoparticles from bamboo leave ash is $50.2 \%$, which is less than rice husk ask resources $(62.1 \%)$, the bamboo waste is only an inexpensive resource yielding high purity (99\%). Synthesis of silica nanoparticles from natural resources/waste with the help of lucrative route is at present times one of the anticipating strategies for extensive applications. In vitro study on animal cell lines (MG63) shows non-toxic nature of silica nanoparticles up to $125 \mu \mathrm{g} \mathrm{mL}^{-1}$. Hence, this study highlights the feasibility for the mass production of silica nanoparticles from bamboo leave waste rather using chemical precursor of silica for drug delivery and other medical applications.
\end{abstract}

Keywords Bamboo leaf biomass - Mass production . Silica nanoparticles · Biocompatibility $\cdot$ Drug delivery

Rajendran Venkatachalam

veerajendran@gmail.com

1 Centre for Nano Science and Technology, K. S. Rangasamy College of Technology, Tiruchengode 637215, Tamil Nadu, India

\section{Introduction}

Amorphous silica nanoparticles are commonly known to have a wide range of applications in many industries. The use of silica nanoparticles are extensive in biomedical field by synthesizing as a good biocompatible nanomaterial which can be used in drug delivery (Huang et al. 2014), enzyme encapsulation (Ab Wab et al. 2014), stabilising agent in therapeutics ( $\mathrm{Lu}$ et al. 2010) and other therapeutic applications ( $\mathrm{Li}$ et al. 2012). In addition, agricultural application of amorphous nanosilica has also been inspected in our previous study to overcome the shortage of silica in soil as well as bio-control action in plants and to enhance morphological and physiological parameters and diseases resistance (Suriyaprabha et al. 2012, 2014).

At present, the lucrative production of amorphous nanosilica is high on demand owing to its wide utility from medical to agriculture. Mass production of desirable and abundantly used biocompatible silica nanoparticles at low cost is essential to meet out the scarcity of using natural resource materials. While evaluating numerous chemical synthesis approaches, extraction of silica nanoparticles from biomass/biological resources is deemed to be one of the most economical production routes. As it is found in monocotyledonous plants, accumulation of silicon is found to be of greater extent (Epstein 1999; Savant et al. 1999). The production of silica nanoparticles is anticipated to be non-toxic and economic in nature. An investigation on forming amorphous silica nanoparticles from rice husk (RH) biomass is studied for different applications (Kalapathy et al. 2000; Carmona et al. 2013; Wong et al. 2014). However, finding the lucrative resources for large scale production of silica nanoparticles is still need to be refined as RH is also useful in animal feeds.

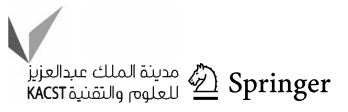


Bamboo is considered as one of the fast growing and highest yielding natural resources which is profusely available for construction from material to mankind. Countries that are rich in bamboo utilizes it for construction and pulp production (Villar-Cocina et al. 2014), thereby leaving the bamboo leaves as waste. Bamboo leave ash (BLA) is formerly studied for the production of pozzolanic material in cement composites (Amu and Adetuberu 2010). Indeed, the chemical analysis of the BLA showed that the concentration of combined Silica, Alumina, and Ferrous oxide exceeds $70 \%$ minimum standard required for pozzolanic materials (Utodio et al. 2015). Similarly, RH, bamboo also has more than $41 \%$ of $\mathrm{SiO}_{2}$ in mature leaves (Motomura et al. 2002). However, to precisely evaluate the nanosilica productivity, both bamboo and RH biomass needs to be examined for pilot scale production so that lucrative synthesis of nanosilica with high purity for biological/industrial applications can be predicted.

One of the important aspects in the application of silica nanoparticles for biomedical applications is to assess the cytotoxicity levels in the living systems (Mondal et al. 2011; Dimkpa et al. 2012). Thus, it becomes an important issue to study the effect of size, shape, and surface functional groups on the bioavailability, uptake, subcellular distribution, metabolism, and degradation of the prepared nanoparticles.

To our knowledge, the extraction of high purity amorphous silica nanoparticles from BLA for industrial applications is scanty. Therefore, in this study, we synthesize silica nanoparticles from bamboo leaves using acid precipitation and characterize their structure, morphology, purity and yield with the help of varied characterization techniques. To substantiate the biomedical importance of the prepared bamboo leaf derived silica nanoparticles, the investigation on biocompatibility of the prepared particles is essential to screen the in vitro cytotoxic effect against animal cell lines.

\section{Materials and methods}

The leaves of bamboo species named Dendrocalamus strictus (Roxb.) Nees were collected in the surrounding areas of Yercaud hills, Salem district, Tamil Nadu, India. Mesophyll cells and parallel veins of the leaves of bamboo are used churn out bamboo leaf ash. All compounds which were used for the extraction were analytical grade and they were used as procured from Merck, India.

\section{Extraction of nanosilica}

The bamboo leaves were thoroughly cleansed so as to eradicate sandy and dust particles. Later, the leaves were dried and leaf powder was heated in the muffle furnace at $1023 \mathrm{~K}$ in an indigenous high temperature for $3 \mathrm{~h}$. The obtained bamboo leaf ash (BLA) was treated with $6 \mathrm{~N} \mathrm{HCl}$ under stirring at $343 \mathrm{~K}$ for $1.5 \mathrm{~h}$ to filter gathered impurities. Silica nanoparticles were extorted from BLA by means of acid precipitation process followed by alkali extraction (Palanivelu et al. 2014; Yuvakkumar et al. 2014). Then, the ash was rinsed for three times with distilled water to acquire the $\mathrm{pH}$ value 7.0. Later on, sodium hydroxide $(2.5 \mathrm{~N})$ was added under stirring for $2 \mathrm{~h}$ at $353 \mathrm{~K}$ to obtain silicate from ash of bamboo leaves. Supernatant consisting of the obtained sodium silicate $\left(\mathrm{Na}_{2} \mathrm{SiO}_{3}\right)$ was added drop by drop with concentrated sulphuric acid until the $\mathrm{pH}$ level reaches 2.5 at which the solution became transparent white silica sol. The $\mathrm{pH}$ level was adjusted to acquire the precipitate of silica solution, and then it was carefully washed with double distilled water to shun the elements of sodium. The silica that was derived was set to dry in a hot air oven at $60{ }^{\circ} \mathrm{C}$ for $36 \mathrm{~h}$. Finally, the pure silica powder was collected after calcination at $723 \mathrm{~K}$ for $2 \mathrm{~h}$. All these processes are carried out in an indigenously designed high temperature tubular muffle furnace reactor set-up to produce silica nanoparticles at large scale.

\section{Muffle furnace reactor set-up}

The photographic image of the indigenous set-up is given in Fig. 1. High temperature tubular muffle furnace reactor set-up is indigenously designed to produce silica nanoparticles from bamboo leaf ash for mass production. High temperature tubular muffle furnace reactor set-up is designed with two major compartments namely, a) High Temperature Tubular Rotating Muffle Furnace and b) Glass Reactor. Tubular furnace set-up is designed in connection with a geared motor to facilitate slow circular rotation with uniform burning of the leaves. One of the salient features of this reactor set-up is the heavy weight rod that was fitted at the bottom of the furnace to tilt the furnace in a horizontal axis by dumble action hand. It is a cost effective way to harvest the burnt ash in collector vessel/glass reactor. The transparent cylindrical glass vessel acts as a collecting drum where silica nanoparticles are extracted from the bamboo leaf ash. Glass container is built-in with the acidproof Teflon blades connected to a motor to achieve homogeneous stirring of the solution. The automated reactor set-up aids in the mass production of silica nanoparticles from bamboo wastes.

\section{Characterization of nanosilica}

Synthesized powders were subjected to various characterization studies for discovering their structure and 


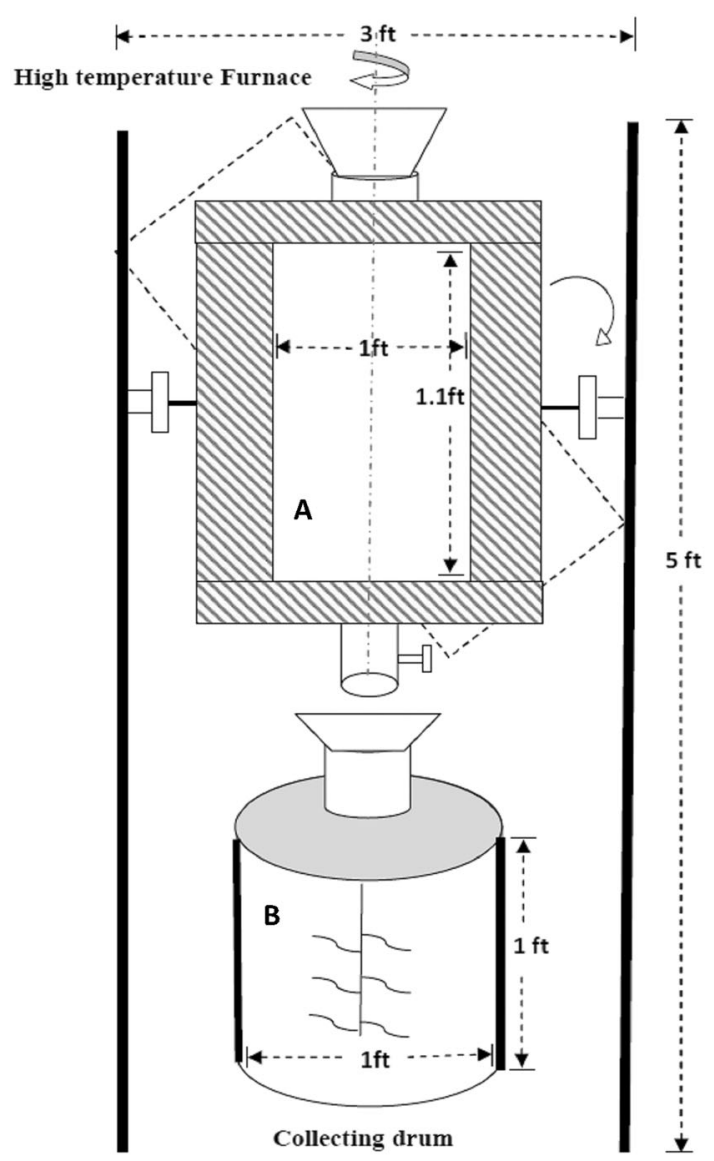

Fig. 1 Block diagram of the indigenous high temperature tubular muffle furnace reactor

morphology. X-ray diffractometer (XRD) (X' Pert Pro, PANalytical, the Netherlands) using $\mathrm{Cu} \mathrm{K}_{\alpha}(\lambda=1.5406 \AA)$ as a radiation source over the $2 \theta$ range of $10^{\circ}-80^{\circ}$ at $293 \mathrm{~K}$ was used to explore the crystalline nature of silica nanoparticles. The peaks of silica functional groups were attained from the Fourier transform infrared spectra (FTIR) in the wave number region of $4000-400 \mathrm{~cm}^{-1}$ with the help of FTIR spectrometer (Spectrum 100, PerkinElmer, USA). Particle size analysis (Nanophox, Sympatec, Germany) of dispersed silica nanoparticles was done to derive particle size distribution curve. The specific surface area of the prepared silica nanoparticles was investigated by means of Brunauer-Emmett-Teller (BET) surface area analyzer (Autosorb AS-1MP, Quantachrome, USA) through $\mathrm{N}_{2}$ adsorption-desorption measurements. The specific surface area (SSA) was estimated from the relative pressure and volume of an adsorbate gas founded on BET equation (Brunauer et al. 1938). Silica nanoparticles were observed for its morphology and size using transmission electron microscopy (TEM) (CM 200, Philips, USA). The morphology and elemental composition of nanosilica was calculated employing scanning electron microscopy coupled with energy dispersive X-ray examination (SEMEDAX) (JEOL JSM-6390LV, Japan).

\section{Dry weight percentage}

A quantity of the bamboo dried leaves was burnt at $1023 \mathrm{~K}$ at the indigenous high temperature muffle furnace for $3 \mathrm{~h}$. Then, the obtained ash was weighed in digital microbalance (AUX- 220, Shimadzu, Japan). The dry weight percentage of nanosilica from BLA is measured with the help of the following relation:

Dry weight percentage $(\%)=\frac{\text { Weight of the ash }(\mathrm{g})}{\text { Weight of leaves }(\mathrm{g})} \times 100$

\section{Elemental analysis}

Different parts (leaf and stem) of the bamboo were amassed and the $\mathrm{SiO}_{2}$ deposition was quantified employing X-ray fluorescence (XRF) spectrometry (EDX-720, Shimadzu, Japan). Qualitative and quantitative elemental study of young and mature leaf, and stem ash of bamboo samples were carried out using XRF. The powder samples were examined directly at $10 \mathrm{~mm} / 5 \mathrm{~mm}$ of focussing on Mylar thin film without any sample preparation and destruction.

\section{Cytotoxicity study}

The silica nanoparticles used for biomedical applications are ultimately affects human cells; hence, they were screened to ascertain the biocompatibility of the particles via cytotoxicity assay against osteoblast-like MG-63 cell line. The MG-63 cell line was purchased from National Centre for Cell Sciences, Pune, India. The cells were cultured in RPMI (Roswell park memorial institute)-1640 medium supplemented with $10 \%$ heat-inactivated foetal bovine serum, $3 \%$ L-glutamine, $100 \mathrm{U} \mathrm{mL}^{-1}$ penicillin $\mathrm{G}$ and $100 \mu \mathrm{g} \mathrm{mL}^{-1}$ streptomycin grown at $310 \mathrm{~K}$ in a humidified atmosphere of $5 \% \mathrm{CO}_{2}$ in air. When the cells attain $80-90 \%$ confluence, they were seeded into 96-well microtitre plate at a density of $1 \times 10^{3}$ cells per well for 3-(4,5-dimethylthiazol-2-yl)-2,5-diphenyl tetrazolium bromide (MTT) assay. After $24 \mathrm{~h}$ of incubation, filter-sterilised nano silica at different concentrations from 1 to $500 \mu \mathrm{g} \mathrm{mL}^{-1}$ were loaded in wells, and again incubated at $310 \mathrm{~K}$ for $48 \mathrm{~h}$. Then, $80 \mu \mathrm{g} \mathrm{mL}^{-1}$ MTT solutions were added into each well and incubated for $4 \mathrm{~h}$. At the end of incubation, $1 \mathrm{~mL}$ of dimethyl sulfoxide was added to reduce the formazan crystals into pink colour. Then, the optical density (OD) of the test samples was read at $570 \mathrm{~nm}$ spectrophotometrically (U-2900, Hitachi, Japan) 
Table 1 Elemental compositions of bamboo leaf ash and rice husk ash

\begin{tabular}{|c|c|c|c|c|c|}
\hline Analyte (\%) & Young leaf powder & Mature leaf powder & BLA (young) & BLA (mature) & RHA \\
\hline $\mathrm{K}$ & 39.793 & 45.091 & 27.527 & 18.545 & 26.764 \\
\hline $\mathrm{Si}$ & 35.337 & 27.835 & 36.469 & 49.881 & 60.550 \\
\hline $\mathrm{S}$ & 8.841 & 11.662 & 9.009 & 10.105 & 0.071 \\
\hline $\mathrm{Ca}$ & 14.468 & 11.579 & 23.230 & 20.006 & 1.901 \\
\hline $\mathrm{P}$ & 0.736 & 3.145 & 0.793 & 1.080 & 9.497 \\
\hline $\mathrm{Fe}$ & 0.496 & 0.306 & 1.916 & 0.173 & 0.684 \\
\hline $\mathrm{Ti}$ & 0.172 & 0.106 & 0.464 & 0.093 & 0.116 \\
\hline $\mathrm{Mn}$ & 0.086 & 0.097 & 0.178 & 0.085 & 0.366 \\
\hline $\mathrm{Cu}$ & 0.046 & 0.049 & 0.047 & 0.009 & 0.013 \\
\hline $\mathrm{Zn}$ & 0.018 & 0.022 & 0.082 & 0.016 & 0.025 \\
\hline $\mathrm{Sr}$ & 0.008 & - & 0.174 & 0.008 & 0.006 \\
\hline $\mathrm{Zr}$ & - & - & 0.008 & - & 0.001 \\
\hline
\end{tabular}

with $630 \mathrm{~nm}$ as the control. The treatment induced morphological changes are observed under microscope (Carl Zeiss PrimoVert ${ }^{\mathrm{TM}}$ Inverted Microscope, Germany) to explore the particle biocompatibility with MG-63 cell line.

\section{Results and discussion}

The percentage composition of young and old leaves, BLA and RHA is examined from the X-ray florescence spectra as listed in Table 1. The yield percentage is comparatively less in the younger leaves than the mature ones. Therefore, the green and mature leaves are burnt so as to obtain the residue from bamboo leave and compared with RHA. It is obvious from the fact that accumulation and distribution of silica bodies present in bamboo leaves are of large intensities especially in mature leaves on a dry weight basis (Motomura et al. 2002).

HR-SEM results (Fig. 2) exhibit the accumulation pattern of siliceous compounds in leaves. Wide and dense deposition of silica is confirmed through the reflection of silica in mature leaves. This microscopic observation supports the elemental composition analysed from XRF analysis. The silica content is found to be high in $\mathrm{RH}$ $(60.55 \%)$ than bamboo (49.88\%). However, the demand for rice husk in different industrial applications like feed and energy etc. (Yalcin and Sevinc 2001; Ramchandra Pode 2016), an alternate cost effective source for silica can be considered from bamboo leaves for the mass production of silica nanoparticles. Burning of the bamboo leaves are comfortable for an industry to attain consistent burning since it is a light weight material.

In the first stage, bamboo leaves are fired in an open atmosphere and then in a muffle furnace reactor to acquire ash containing the white amorphous silica. The indigenous reactor set-up aids the continuous processing of the biomass into silica particles at large scale. A mass percentage (20\%) is acquired as white ash from the bamboo leave powder after burning. Metal impurities are removed during acid leaching of BLA under magnetic blending for $1.5 \mathrm{~h}$. Then, the colourless extract of $\mathrm{Na}_{2} \mathrm{SiO}_{3}$ is found with the treatment of $\mathrm{NaOH}$. Silica gel is formed when the $\mathrm{Na}_{2} \mathrm{SiO}_{3}$ solution is allowed to the treatment of Con. $\mathrm{H}_{2} \mathrm{SO}_{4}$. The white silica powder is attained after calcinations at $723 \mathrm{~K}$. The schematic representation of synthesis route using the high temperature tubular furnace reactor set-up during the extraction of silica nanoparticles from BLA is given in Fig. 3. The chemical reaction rate and reaction kinetics are calculated for the preparation of silica nanoparticles. Reaction rate for the entire extraction process for producing white transparent silica precipitate from BLA is calculated as $0.286 \mathrm{~g} \mathrm{~h}^{-1}$ based on the following formula:

$$
\begin{aligned}
\text { Reaction rate }= & \text { quantity of product produced }(\mathrm{g}) / \\
& \text { time interval }(\mathrm{h})
\end{aligned}
$$


The following are possible chemical reaction occurs during the extraction process from bamboo leave biomass: favoured the agro-biotechnological application as it is considered safe for humans by the World Health Organization (WHO). Hence, it has the demand to be extensively

$$
\begin{gathered}
\text { Bamboo leave ash (BLA) }+\mathrm{HCI} \\
\mathrm{BLA}+4 \mathrm{NaOH} \\
2 \mathrm{Na}_{2} \mathrm{SiO}_{3}+2 \mathrm{H}_{2} \mathrm{SO}_{4} \\
\mathrm{Si}(\mathrm{OH})_{4}(\mathrm{Wet}) \\
\mathrm{Si}(\mathrm{OH})_{4}(\text { Dry })
\end{gathered}
$$

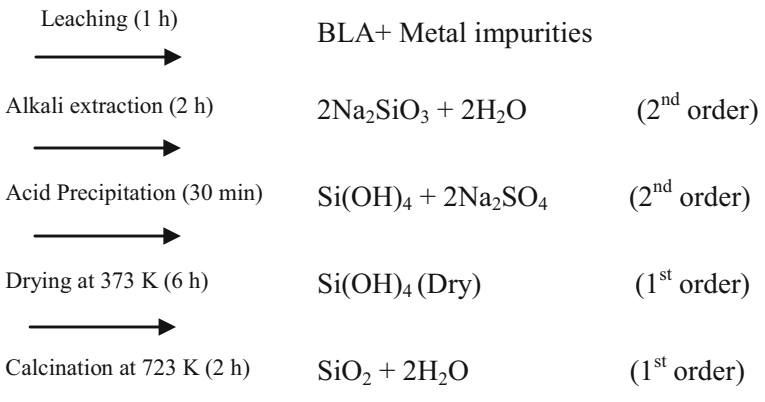

The physico-chemical characteristics of the prepared silica nanoparticles are broadly evaluated. X-ray diffraction spectra of the prepared silica powder reveal a highly amorphous nature, which corresponds with the strong broad band localized at $22^{\circ}(2 \theta)$ (Fig. 4a). The existence of crystalline minerals was not discovered in the spectra with devoid of contaminants like sodium sulphate and other metals. These pure amorphous particles are highly used in materials such as fillers, pharmaceuticals, catalysts, and chromatography (Bakaev and Pantano 2009).

The specific functional groups correspond to silica nanoparticles are viewed from the FTIR absorption spectra which illustrates the purity of silica nanoparticles (Fig. 4b). The peak at $467 \mathrm{~cm}^{-1}$ corresponds to bending vibrations of $\mathrm{Si}-\mathrm{O}-\mathrm{Si}$ groups. The observed sharp peak at $809 \mathrm{~cm}^{-1}$ and the short peak at $619 \mathrm{~cm}^{-1}$ reveal the existence of $\mathrm{Si}-\mathrm{O}$
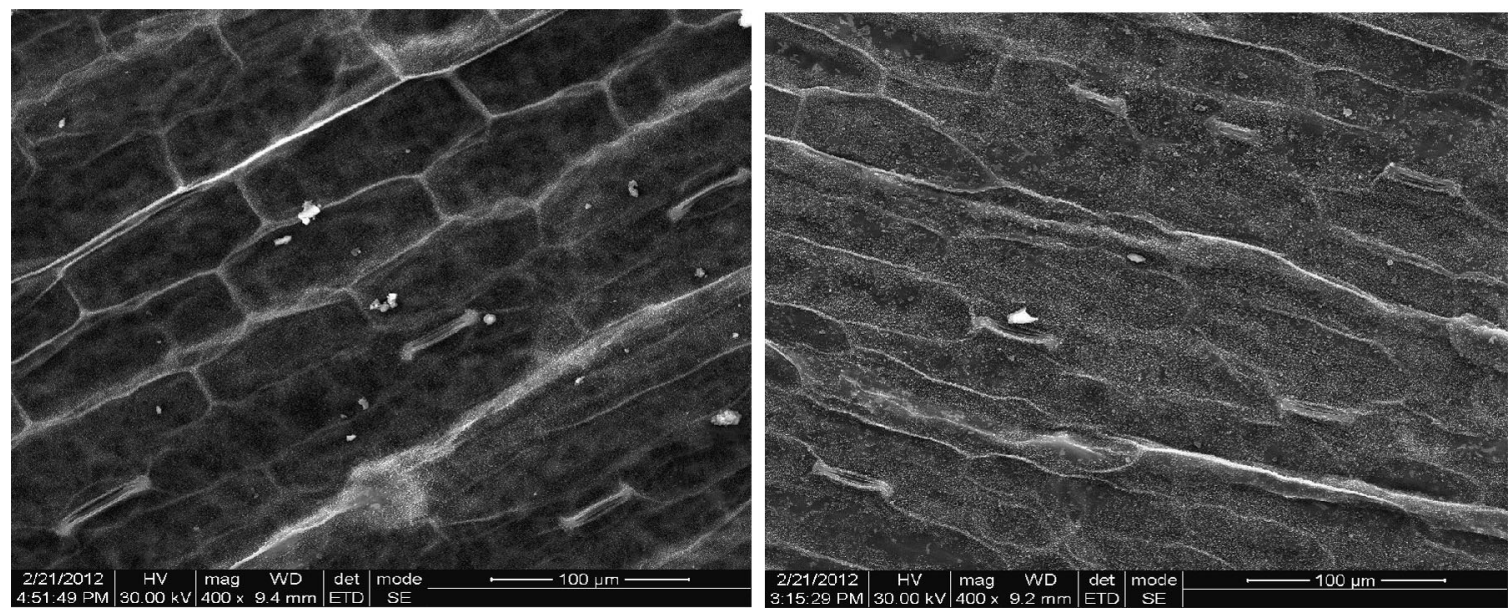

Fig. 2 HRSEM image of the young and mature leaf blades of bamboo

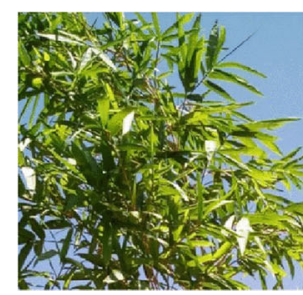

Bamboo leaves

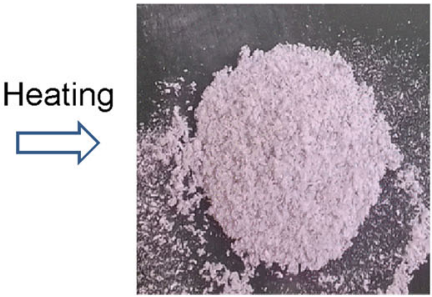

Leaf ash

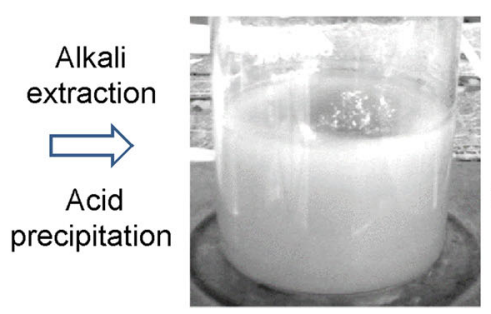

Silica sol

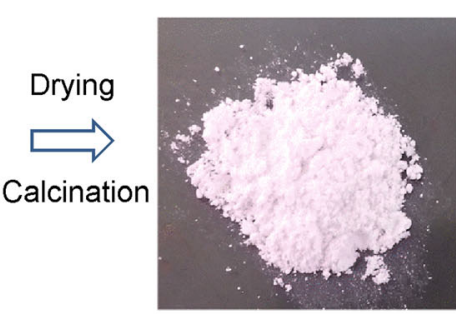

Nano silica powder

Fig. 3 Schematic representation of synthesizing silica nanoparticles from bamboo leaf biomass 


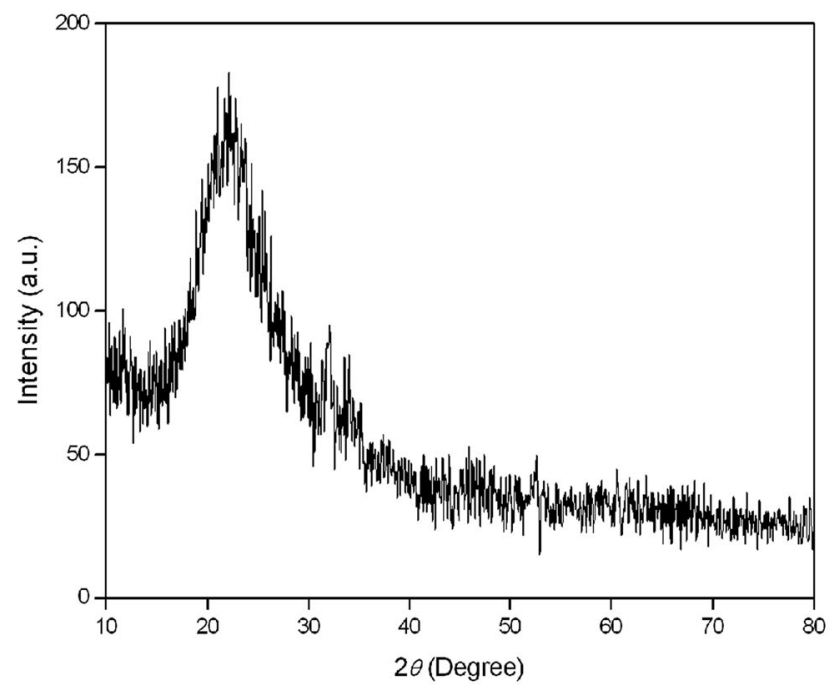

(A) XRD

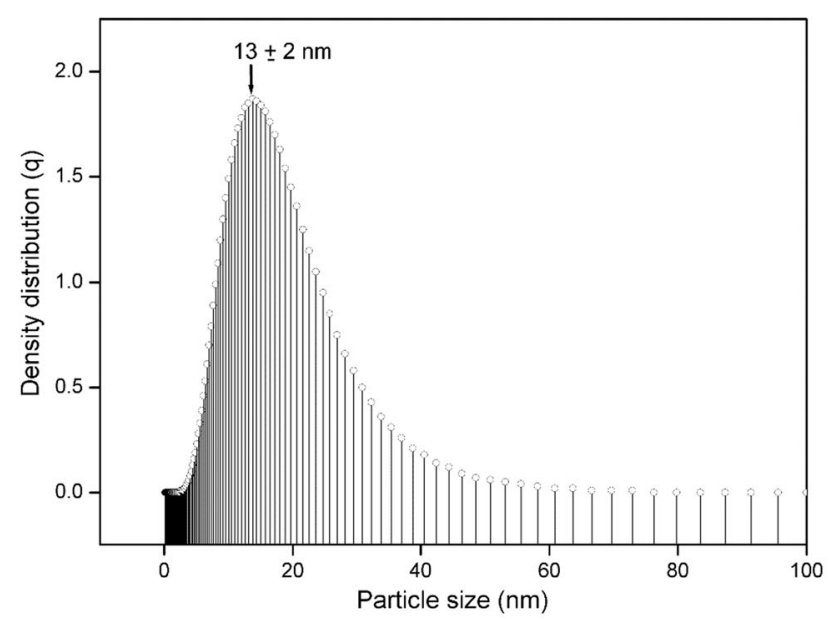

(C) Particle size Distribution

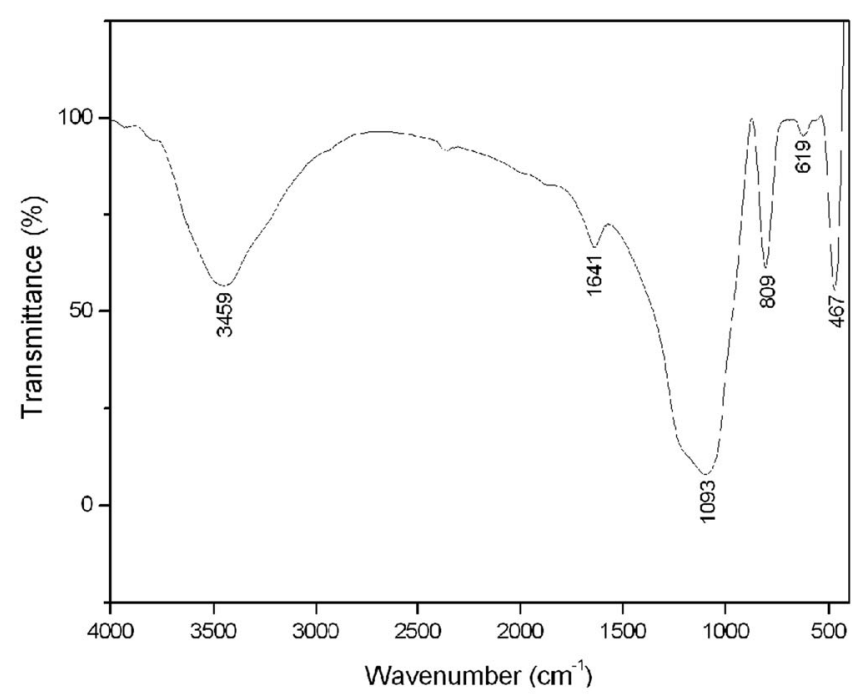

(B) FTIR

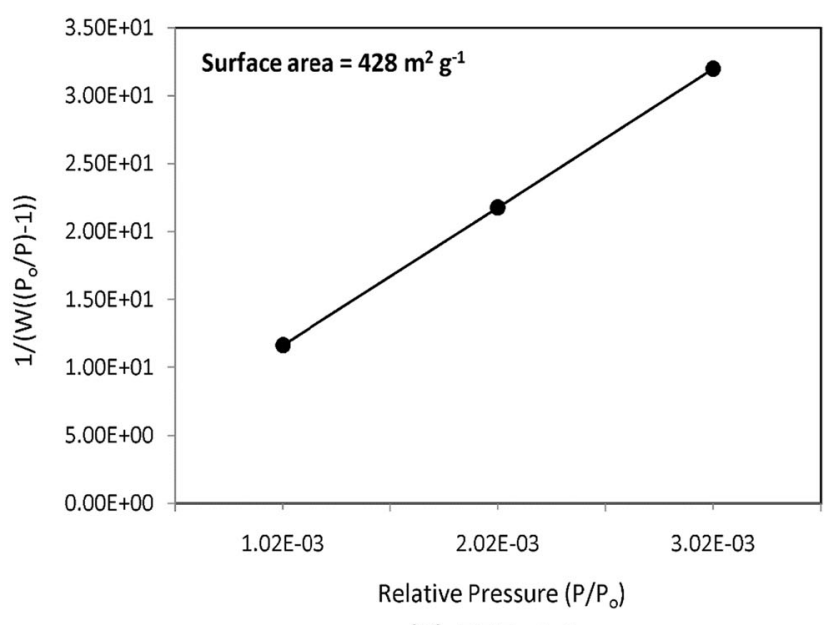

(D) BET plot

Fig. 4 Structural and textural characteristics of the prepared silica powder from bamboo leaf biomass

bending vibrations. The peak shift seen from 1052 to $1093 \mathrm{~cm}^{-1}$ assigned to an asymmetric siloxane ( $\mathrm{Si}-\mathrm{O}-\mathrm{Si}$ ) stretching vibration (Suriyaprabha et al. 2012) signifies the arrangement of bonding structures of $\mathrm{Si}$ and $\mathrm{O}$ atoms towards smaller particle size, i.e. nanoscale (Rahman et al. 2009). A broad band in the range of $3200-3600 \mathrm{~cm}^{-1}$ is due to the silanol $-\mathrm{OH}$ groups and adsorbed water. The peak arrangements of FTIR spectrum are not found to have significant difference in the prepared nanosilica from bamboo and rice husk. However, the reduction in particle size is observed in bamboo.

The research of particle size distribution through dynamic light scattering displays the broad distribution range of particles from $3\left(\mathrm{~d}_{10}\right)$ to $60\left(\mathrm{~d}_{90}\right)$ (Fig. $\left.4 \mathrm{c}\right)$. The mean size distribution of the particles is found to be $13.8 \pm 2 \mathrm{~nm}$. BET surface area of the silica particles is found to be very high $\left(428 \mathrm{~m}^{2} \mathrm{~g}^{-1}\right)$ as observed from the plot (Fig. 4d) derived from nitrogen absorption-desorption process. As derived from our previous survey records, it is clear that this is distribution is comparatively larger when compared to RH derived silica nanoparticles $\left(360 \mathrm{~m}^{2} \mathrm{~g}^{-1}\right)$. The TEM image of the sample displays the transparent spherical silica particles in the size range of $10-60 \mathrm{~nm}$ (Fig. 5a) and their selected area energy diffraction (SAED) pattern (inset of Fig. 3a) reveals the diffusive ring pattern corresponding to amorphous silica which is also confirmed from XRD spectra. Moreover, these characteristics of SNPs are confirmed with the results obtained for rice husk in our previous studies (Suriyaprabha et al. 2012; Palanivelu et al. 2014). The scanning electron micrograph of the organized silica powders illustrates the smaller and discrete particles with slight aggregation and displays spherical morphology as seen in Fig. 5b. The EDX spectrum of the corresponding SEM observation confirms the purity of silica nanoparticles 


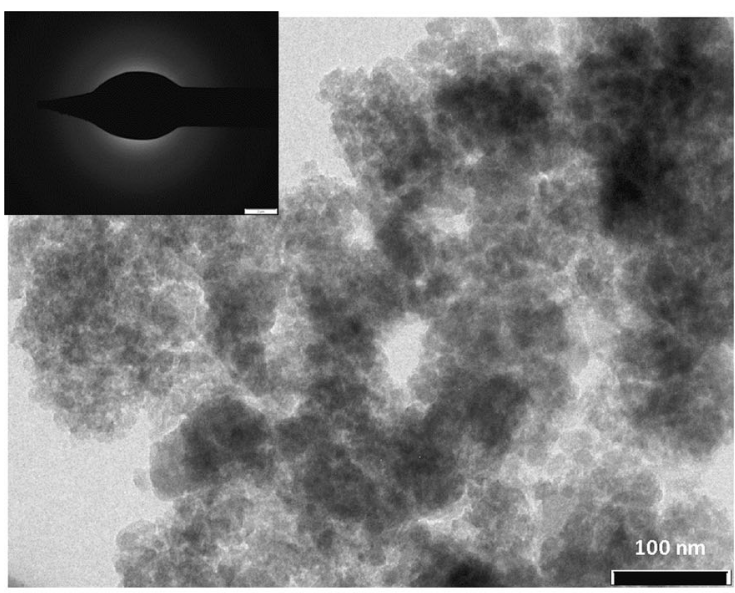

(A) TEM

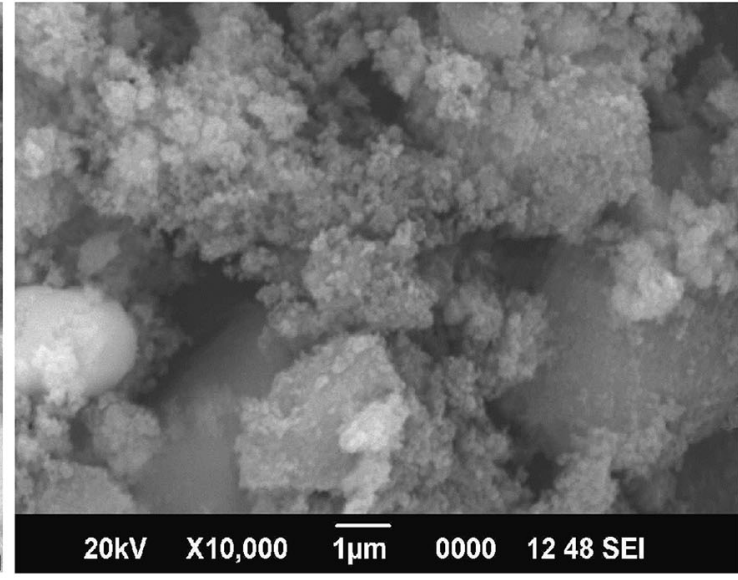

(B) SEM

Fig. 5 Scanning and transmission electron micro graphical image of the extracted silica particles

as $99.1 \%$. Therefore, the endeavour for producing high purity and high surface area silica particle from BLA for biomedical applications are more beneficial and it can be further used to demonstrate precise and sensitive results.

On the other hand, the usage of the bamboo residue for practical applications is lower while the demand for rice husk is high for different applications (Ramchandra Pode 2016). Their purity and dry weight percentage are compared with the silica which is mined from the RH. The yield percentage $(\%)$ of silica from BLA gained in the present analysis is $50.2 \%$ as obtained from this following equation:

$$
\begin{aligned}
& \text { Yield percentage }(\%) \\
& =\frac{\text { Quantity of silica nanoparticles synthesized }(\mathrm{g})}{\text { Quantity of BLA used }(\mathrm{g})} \times 100
\end{aligned}
$$

It is interesting to note that the yield percentage of $\mathrm{RH}$ derived silica is higher $(60.1 \%)$ than BLA. However, the bamboo waste is merely low cost resource yielding high purity (99\%) than RHA (97\%) as evidenced from our previous investigations (Suriyaprabha et al. 2012; Palanivelu et al. 2014). The production cost of amorphous silica nanoparticles varies from 700 to 6000 INR based on the purity grades (Industrial, agricultural and food Grade) of the silica and precursor. While comparing the rice husk as a source for silica, bamboo reduces the cost of production by neglecting the investment for buying rice husk from industry because matured and senescence bamboo leaves is littered as a waste in forest. Hence, $40 \%$ of the expense for the source materials is reduced while using bamboo leaves for nanosilica production. In addition, synthesized silica nanoparticles from BLA possess high surface area with improved purity percentage than the particles produced from RHA. The observed difference in silica accumulation between two plants of different parts is also in line with the previous statement that the ability of plants to accumulate $\mathrm{Si}$ varies greatly between species $(0.1-10 \%$ of shoot dry weight). Furthermore, different parts of the same plant can illustrate large differences in $\mathrm{Si}$ accumulation (Hodson and Evans 1995; Currie and Perry 2007).

The morphological changes in MG-63 cell lines with the treatment of different concentrations of silica nanoparticles reveal the non-significant variations (Fig. 6) and cell death which is also confirmed by MTT assay. Concentration of particles above $100 \mu \mathrm{g} \mathrm{mL}^{-1}$ shows an increased accumulation of silica within the cells causing cell detachment, and aggregation of particles in culture media as seen in Fig. 6. The cytotoxic response of osteoblast cells to the treatment of different concentrations of silica nanoparticles

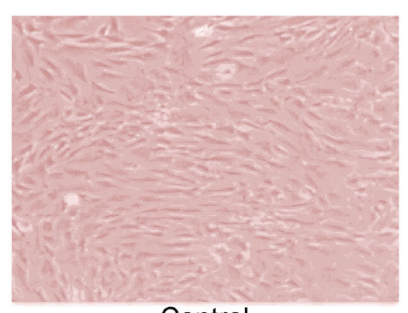

Control

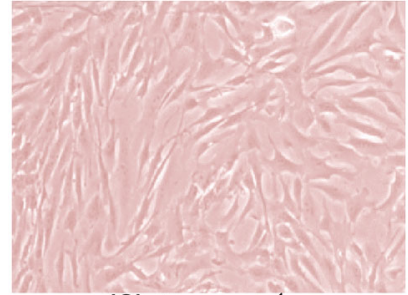

(C) $50 \mu \mathrm{g} \mathrm{mL}^{-1}$

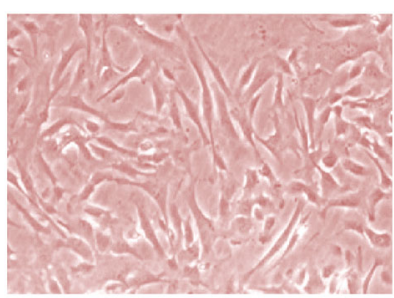

(B) $25 \mu \mathrm{g} \mathrm{mL}$
Fig. 6 Morphological changes with the treatment for silica nanoparticles in MG-63 cell line 


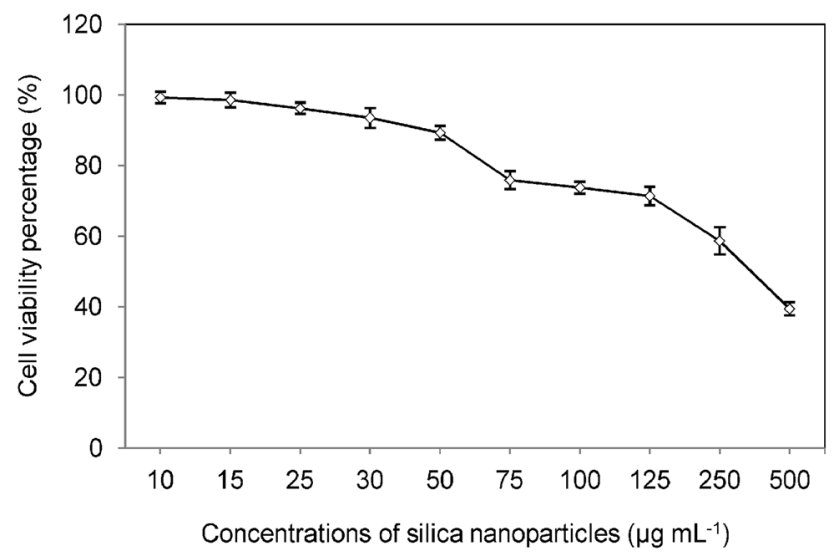

Fig. 7 Percentage of cytotoxicity as a function of treatment of silica nanoparticles

through MTT assay are shown in Fig. 7. From the figure, the total cell viability percentage of MG-63 cells under different concentrations is elucidated against $100 \%$ control samples. Above $100 \mu \mathrm{g} \mathrm{mL} L^{-1}$, cell viability tends to decrease significantly. This may be due to the formation of particle agglomeration in RPMI medium as well as interference during the cell proliferation at high particles concentration which results in decreased cell viability. Conventionally synthesized amorphous nano silica (500 and $50 \mathrm{~nm}$ ) exhibits their potency against Bronchial epithelial lung cells confirming the suitability for pharmacological applications (Skuland et al. 2014). Hence, the in vitro cytotoxic responses of MG-63 cell line to bamboo derived amorphous silica nanoparticles are not showing any toxicological responses exhibiting good biocompatibility which affirms the use of silica nanoparticles for drug delivery applications in future. This cytotoxic study also supports the previous investigations made by Huang et al. (2014) on the use of chemically synthesized silica nanoparticles for drug delivery applications. It is an added advantage that use of cost effective silica at nanoscale prepared from bamboo waste is biocompatible at a very high concentration of treatment to the living system.

\section{Conclusion}

Low energy bio-chemical processing for extraction yields high purity $(98.9 \%)$ amorphous silica nanoparticles in the particle range of $10-60 \mathrm{~nm}$. The availability and production cost of bamboo leave biomass is comparatively lesser than rice husk biomass even though it has higher silica content. The result of the morphological changes and cytotoxic response of silica nanoparticles to osteoblast cell lines reveals the good biocompatibility for further medical applications. As silica is considered to be the one of the most necessitate nanomaterials for biomedical, agricultural and electronic applications, this cost effective technique is an ideal method to devise a model strategy for mass production of biogenic silica nanoparticles.

Acknowledgement One of the authors (Dr. R.S) is thankful to the University Grants Commission (UGC), New Delhi for granting Post Doctoral Fellowship for Women (F.15-1/2015-17/PDFWM-2015-17TAM-36274 dt.12/10/2015).

Open Access This article is distributed under the terms of the Creative Commons Attribution 4.0 International License (http:// creativecommons.org/licenses/by/4.0/), which permits unrestricted use, distribution, and reproduction in any medium, provided you give appropriate credit to the original author(s) and the source, provide a link to the Creative Commons license, and indicate if changes were made.

\section{References}

Ab Wab HA, Abdul Razak K, Zakaria ND (2014) Properties of amorphous silica nanoparticles colloid drug delivery system synthesized using the micelle formation method. J Nanopart Res $16: 2256$

Amu OO, Adetuberu AA (2010) Characteristics of bamboo leaf ash stabilization on lateritic soil in highway construction. Int J Engg Technol 2(4):212-219

Bakaev VA, Pantano CG (2009) Inverse reaction chromatography. 2. Hydrogen/deuterium exchange with silanol groups on the surface of fumed silica. J Phys Chem C 113(31):13894-13898

Brunauer Stephen, Emmett PH, Teller Edward (1938) Adsorption of gases in multimolecular layers. J Am Chem Soc 60(2):309-319

Carmona VB, Oliveira RM, Silva WTL, Mattosoa LHC, Marconcini JM (2013) Nanosilica from rice husk: extraction and characterization. Ind Crop Prod 43:291-296

Currie HA, Perry CC (2007) Silica in plants: biological, biochemical and chemical studies. Ann Bot 100(7):1383-1389

Dimkpa CO, McLean JE, Latta DE, Manangon E et al (2012) CuO and $\mathrm{ZnO}$ nanoparticles: phytotoxicity, metal speciation, and induction of oxidative stress in sand-grown wheat. J Nanopart Res 14(9):1125

Epstein E (1999) Silicon. Ann. Rev. Plant Physiol Plant Mol Biol 50(1):641-664

Hodson MJ, Evans DE (1995) Aluminium/silicon interactions in higher plants. J Exp Bot 46(2):161-171

Huang X, Young NP, Townley HE (2014) Characterisation and comparison of mesoporous silica particles for optimised drug delivery. Nanomater Nanotechnol 4(2):1-15

Kalapathy U, Proctor A, Shultz J (2000) A simple method for production of pure silica from rice hull ash. Bioresour Technol 73:257-262

Li Z, Barnes JC, Bosoy A, Stoddart JF, Zink JI (2012) Mesoporous silica nanoparticles in biomedical applications. Chem Soc Rev 41:2590-2605

Lu J, Liong M, Li Z, Zink JI, Tamanoi F (2010) Biocompatibility, biodistribution, and drug-delivery efficiency of mesoporous silica nanoparticles for cancer therapy in animals. Small 6(16): 1794-1805

Mondal A, Basu R, Das S, Nandy P (2011) Beneficial role of carbon nanotubes on mustard plant growth: an agricultural prospect. J Nanopart Res 13(10):4519-4528 
Motomura H, Mita N, Suzuki M (2002) Silica accumulation in longlived leaves of Sasa veitchii (Carriére) Rehder (PoaceaeBambusoideae). Ann Bot 90(1):149-152

Palanivelu R, Padmanaban P, Sutha S, Rajendran V (2014) Inexpensive approach for production of high-surface-area silica nanoparticles from rice hulls biomass. IET Nanobiotechnol 8(4):290-294

Pode Ramchandra (2016) Potential applications of rice husk ash waste from rice husk biomass power plant. Renew Sust Energ Rev 53:1468-1485

Rahman IA, Vejayakumaran P, Sipaut CS, Ismail J, Chee CK (2009) Size-dependent physicochemical and optical properties of silica nanoparticles. Mater Chem Phys 114:328-332

Savant NK, Snyder GH, Datnoff LE (1999) Silicon management and sustainable rice production. Adv Agronomy 58:151-199

Skuland T, Ovrevik J, Lag M, Refsnes M (2014) Role of size and surface area for pro-inflammatory responses to silica nanoparticles in epithelial lung cells: importance of exposure conditions. Toxicol In Vitro 28(2):146-155

Suriyaprabha R, Karunakaran G, Yuvakkumar R, Rajendran V, Prabu P, Kannan N (2012) Growth and physiological responses of maize (Zea mays L.) to porous silica nanoparticles in soil. J Nanopart Res 14:1-14
Suriyaprabha R, Karunakaran G, Yuvakkumar R, Rajendran V, Kannan N (2014) Augmented biocontrol action of silica nanoparticles and Pseudomonas fluorescens bioformulant in maize (Zea mays L.). RSC Adv 4:8461-8465

Utodio NF, Ekandem ES, Egege CC, Ocholi M, Atakpu OD, Nwaigwe DN (2015) Investigation of the effect of bamboo leaf ash blended cement on engineering properties of lateritic blocks. J Sustain Dev Stud 8(1):193-208

Villar-Cocina E, Morales EV, Santos SF, Savastano H, Frias M (2014) Pozzolanic behavior of bamboo leaf ash: characterization and determination of the kinetic parameters. Cement Concrete Comp 33(1):68-73

Wong DP, Suriyaprabha R, Yuvakumar R, Rajendran V, Chen Y-T, Hwang B-J, Chen L-C, Chen K-H (2014) Binder-free rice huskbased silicon-graphene composite as energy efficient Li-ion battery anodes. J Mater Chem A 2:13437-13441

Yalcin N, Sevinc V (2001) Studies on silica obtained from rice husk. Ceram Int 27:219-224

Yuvakkumar R, Elango V, Rajendran V, Kannan N (2014) Highpurity silica nanoparticles powder from rice husk using a simple chemical method. J Exp Nanosci 9(3):272-281 